\title{
Safety of transition from a routine to a selective intensive care admission pathway after elective open aneurysm repair
}

\author{
Danielle Dion, MD \\ Laura Marie Drudi, MD, MSc \\ Nathalie Beaudoin, MD \\ Jean-François Blair, MD \\ Stéphane Elkouri, MD, MSc
}

Presented at the 37th Annual Meeting of the Canadian Society for Vascular Surgery, Sept. 25-26, 2015, Victoria, BC.

Accepted Feb. 25, 2020

\author{
Correspondence to: \\ S. Elkouri \\ Centre hospitalier universitaire de \\ Montréal \\ 1000 rue St-Denis \\ Montreal QC H2X 0C1 \\ stephane.elkouri@umontreal.ca
}

DOI: $10.1503 /$ cjs.012518

\begin{abstract}
Background: There is a growing trend to implement intermediate care units to avoid unnecessary costs associated with intensive care unit (ICU) admission and associated resources. We sought to evaluate the safety of transitioning from a routine to a selective policy of postoperative transfer to the ICU for elective open abdominal aortic aneurysm (AAA) repair.

Methods: This retrospective study included consecutive open elective AAA repair procedures performed at a single centre from Aug. 8, 2010, to Dec. 1, 2014. Patients were identified through a prospectively maintained database, and electronic charts were reviewed. Patients with interventions before Mar. 13, 2012, were routinely sent to the ICU after operation (group A). Patients treated after this date were sent directly to an intermediate care unit (group B) unless preoperative or intraoperative factors deemed them suitable for ICU admission. The primary outcome was in-hospital death; secondary outcomes were perioperative complications and length of stay. We used logistic and linear regression to determine the association between the use of an intermediate care unit and the primary and secondary outcomes after adjusting for confounders and clinically relevant covariates.
\end{abstract}

Results: The cohort comprised 310 patients (266 men, 44 women) with a mean age of 69.7 (standard deviation 10.1) years and a mean AAA diameter of $61.2 \mathrm{~mm}$ (SD $9.6 \mathrm{~mm}$ ). Groups A and B included 118 and 192 patients, respectively. Admission to the ICU was spared in 149 patients (77.6\%) in group B. Only 2 patients $(1.3 \%)$ in group B were subsequently admitted to the ICU. There was no statistically significant difference in in-hospital mortality or perioperative complications between the 2 groups on multivariable logistic regression. There was a nonsignificant trend toward slightly shorter length of stay in group B.

Conclusion: In this single-centre experience with the majority of patients sent directly to an intermediate care unit, there was no statistically significant difference in mortality or morbidity between routine and selective ICU admission. Our results confirm the safety of a selective ICU admission pathway.

Contexte : La tendance est à la création d'unités de soins intermédiaires pour éviter les coûts inutiles entraînés par les séjours aux unités de soins intensifs (USI) et les ressources associées. La présente étude visait à évaluer la sécurité d'un transfert aux USI sélectif, plutôt que systématique, après la réparation ouverte élective d'un anévrisme aortique abdominal (AAA).

Méthodes : Cette étude rétrospective portait sur des réparations ouvertes électives d'AAA consécutivement réalisées à un même centre pour la période du 8 août 2010 au $1^{\text {er }}$ décembre 2014. Nous avons recensé les cas dans une base de données maintenue de manière prospective, puis avons étudié les dossiers électroniques. Les patients opérés avant le 13 mars 2012 ont été envoyés d'emblée à l'USI après l'intervention (groupe A). Ceux traités après cette date ont été transférés directement en soins intermédiaires (groupe B), sauf s'ils se qualifiaient pour l'admission à l'USI en raison de facteurs préopératoires ou intraopératoires. Le principal résultat à l'étude était les décès à l'hôpital; les résultats secondaires étaient les complications périopératoires et la durée du séjour. Un modèle de régression logistique a servi à déterminer les associations entre le transfert direct en soins intermédiaires et les résultats primaire et secondaires en tenant compte des facteurs de confusion et des covariables pertinentes sur le plan clinique.

Résultats : La cohorte regroupait 310 patients (266 hommes et 44 femmes) dont l'âge moyen était de 69,7 ans (écart-type 10,1) et le diamètre moyen de l'AAA était de 61,2 mm (ET 9,6 mm). Les groupes A et B comptaient 118 et 192 patients, respectivement. L'admission aux soins intensifs a été évitée chez 149 patients (77,6\%) du groupe B. Seuls 2 $(1,3 \%)$ d'entre eux ont dû être admis à l'USI après coup. La régression logistique multivariable n'a montré aucune différence statistiquement significative entre les groupes à l'égard de la mortalité à l'hôpital et des complications périopératoires. Nous avons noté une réduction non significative de la durée de séjour pour le groupe B.

Conclusion: Cette étude monocentrique où la majorité des patients ont été transférés directement en soins intermédiaires n'a pas révélé de différence statistiquement significative à l'égard de la mortalité et de la morbidité entre les admissions systématiques et sélectives aux USI. Nos résultats confirment que l'admission sélective en soins intensifs est une option sécuritaire. 
$\mathrm{H}$ istorically, most patients undergoing elective high-risk vascular surgery procedures, such as aortic aneurysm repair, were routinely sent to the intensive care unit (ICU). The early postoperative period, defined as the first 24-48 hours, was deemed critical in that more rigorous physiologic support was required. Mortality and morbidity with high-risk vascular surgery procedures are often related to perioperative adverse cardiovascular events. In a health care environment focused on making cost-effective use of resources, a newer model of selective postoperative monitoring in the ICU was developed while providing safe and efficient postoperative care: "step-down," or intermediate care, units were implemented on inpatient wards with intermediate monitoring. These intermediate care units include noninvasive hemodynamic cardiac monitoring and a lower patient-tonurse ratio than on regular inpatient wards. Patient care is provided by vascular surgeons and residents in teaching centres but with varying nurse-to-patient ratios, often being 1:2 or 1:3. This selective intermediate care postoperative pathway has been shown to obviate the need for ICU postoperative care while ensuring patient safety. ${ }^{1}$ Centres that have adopted a policy of selective ICU admission after open abdominal aortic aneurysm (AAA) repair have shown it to be a safe practice, with most patients sent directly to an intermediate care unit; few require subsequent ICU admission. ${ }^{2-4}$

There is a growing trend to implement intermediate care units to avoid unnecessary costs associated with ICU admission and related resources. ${ }^{5-7}$ However, not all centres have access to these types of units or the funds necessary to finance their development.

In March 2012, in an effort to reduce health care expenses and focus on cost-effective use of health care resources, the Service de chirurgie vasculaire of the Centre hospitalier universitaire de Montréal changed its policy to selective use of postoperative ICU admission; patients were admitted to an intermediate care unit unless they had prohibitive risk or required more acute care. In this study, we sought to evaluate a single-centre experience regarding the safety of transitioning from a routine to a selective policy of postoperative transfer to the ICU after elective open AAA repair. We also wished to evaluate whether the evidence from this study would support an intermediate care unit pathway, in order to translate this model as standard of care.

\section{Methods}

\section{Design}

We performed a retrospective cohort study at a single centre in Montréal, Quebec. Consecutive patients who underwent elective open AAA repair between Aug. 8,
2010, and Dec. 1, 2014, were identified from a prospectively maintained database. Patients who had surgery before Mar. 13, 2012, were routinely sent to the ICU after operation (group A). Patients treated after this date were sent directly to an intermediate care unit (group B) unless otherwise determined preoperatively by the surgeon or if they experienced intraoperative complications that necessitated admission to the ICU. The study was approved by the Centre hospitalier universitaire de Montréal Research Ethics Board. The paper was prepared in accordance with the Strengthening the Reporting of Observational Studies in Epidemiology (STROBE) guidelines. ${ }^{8}$

\section{Patient selection}

We reviewed electronic patient charts to extract patient characteristics, including major comorbidities (hypertension, diabetes, coronary artery disease, chronic obstructive pulmonary disease, chronic renal failure and history of cerebrovascular events), operative details (aneurysm size, clamping level, type of repair, intraoperative blood loss and need for transfusion), postoperative disposition and postoperative complications. If the data in the charts were incomplete, the paper charts from Medical Archives were consulted and reviewed. Preoperative assessment was conducted by vascular surgeons and internal medicine specialists.

Patients were extubated at the end of the procedure and monitored closely in the recovery unit. If their condition was stable, they did not require any inotropes or vasopressors, and their respiratory status was satisfactory, they were sent to the vascular intermediary care unit after 4 hours in the recovery unit. The intermediate care unit was a decentralized unit located on the vascular surgery ward with a $1: 3$ nurse-to-patient ratio. Patients were provided less invasive hemodynamic monitoring than in the ICU. All patients had cardiac monitoring or telemetry. Arterial and central lines placed intraoperatively by the anesthesia team were able to be maintained in the intermediate care unit; vasopressors and invasive ventilation were not available in the unit. Nurses working in the intermediate care unit received additional specialized training for arterial lines and cardiac monitoring and were certified in electrocardiography.

Patients with severe cardiovascular disease, congestive heart failure, chronic obstructive pulmonary disease with home oxygen requirements or end-stage renal disease requiring dialysis were admitted preemptively to the ICU. Patients with intraoperative or postoperative instability that necessitated massive transfusion $(>3 \mathrm{~L})$, difficult extubation or need for reintubation, or hemodynamic instability requiring vasopressor or inotrope support were also admitted to the ICU. The ICU had a 1:1 nurse-to-patient ratio. 


\section{Outcomes}

The primary outcome was in-hospital death. The secondary outcomes were perioperative morbidity and hospital length of stay (LOS). The outcome assessor (D.D.) was blinded to intermediate care unit admission. As this was a change in practice, we calculated avoidance of ICU admission per year to investigate surgeons' adaptability to the pathway.

\section{Statistical analysis}

We summarized discrete categoric variables with counts and percentages, and continuous variables with sample means and standard deviations (SDs). We compared patient characteristics including age, gender, smoking status and major comorbidities between the 2 groups. We performed univariate analysis to assess the association of intermediate care unit admission and relevant covariates with the study outcomes. We used multivariable logistic regression to estimate the association of intermediate care unit admission with mortality and morbidity, adjusting for age, sex, clamp site and perioperative risk using the Revised Cardiac Risk Index (RCRI). ${ }^{9}$ We used linear regression to estimate the association of intermediate care unit admission with hospital LOS, adjusting for clinically relevant covariates. Models were also stratified by patients who were admitted to the intermediate care unit and those who did not. We performed statistical analyses with RStudio version 0.99.491 (R Corporation for Statistical Computing) and Stata version 14.1 (StataCorp).

\section{Results}

The cohort consisted of 310 adult patients $(265$ men, 45 women) with a mean age of 69.7 (SD 10.1) years. Thirty-four patients (11.0\%) were aged 50-60 years, 104 $(33.5 \%)$ were aged $60-69$ years, $135(43.5 \%)$ were aged $70-79$ years, and 37 (11.9\%) were aged 80 years or older. The mean RCRI score was 1.6 (SD 0.3) points out of 4. Data on in-hospital vital status were complete for all patients. The mean aneurysm diameter, including all infra-, juxta- and pararenal aneurysms, was $61.2 \mathrm{~mm}$ (SD $9.6 \mathrm{~mm}$ ).

A total of 118 patients (38.1\%) had routine admission to the ICU (group A), and 192 (61.9\%) had selective admission to the ICU (group B). The baseline characteristics of the 2 groups are shown in Table 1. Patients in group B had increased suprarenal clamping compared to those in group A (probability difference $17.7 \%, 95 \%$ confidence interval [CI] 6.7-28.6). Other baseline characteristics were equally distributed between the 2 groups.

\section{Morbidity and mortality}

Two patients $(0.6 \%)$ ( 1 in each group) died in hospital, and $76(24.5 \%)$ had a perioperative complication
Table 1. Baseline characteristics of consecutive patients who underwent elective open abdominal aortic aneurysm repair with routine (group A) or selective (group B) admission to the intensive care unit

\begin{tabular}{|c|c|c|c|}
\hline \multirow[b]{2}{*}{ Characteristic } & \multicolumn{2}{|c|}{ No. $(\%)$ of patients* } & \multirow[b]{2}{*}{$p$ value } \\
\hline & $\begin{array}{l}\text { Group A } \\
n=118\end{array}$ & $\begin{array}{l}\text { Group B } \\
n=192\end{array}$ & \\
\hline Gender & & & 0.009 \\
\hline Male & $106(89.8)$ & 159 (82.8) & \\
\hline Female & $12(10.2)$ & $33(17.2)$ & \\
\hline Age, mean $\pm S D$, yr & $69.7 \pm 7.7$ & $70.8 \pm 7.2$ & 0.2 \\
\hline $\begin{array}{l}\text { Aneurysm size, mean } \\
\pm \mathrm{SD}, \mathrm{mm}\end{array}$ & $61.5 \pm 9.1$ & $61.1 \pm 9.9$ & 0.6 \\
\hline \multicolumn{4}{|l|}{ Clamping } \\
\hline Suprarenal & 36 (30.5) & $90(46.9)$ & 0.001 \\
\hline Infrarenal & 82 (69.5) & $102(53.1)$ & 0.004 \\
\hline \multicolumn{4}{|l|}{ Type of repair } \\
\hline Aortoaortic & $91(77.1)$ & $143(74.5)$ & 0.8 \\
\hline Aortobi-iliac & 20 (16.9) & $35(18.2)$ & 0.8 \\
\hline Aortobifemoral & $7(5.9)$ & $14(7.3)$ & 0.6 \\
\hline Transfusion & $19(16.1)$ & $41(21.4)$ & 0.2 \\
\hline Smoker & $61(51.7)$ & $104(54.2)$ & 0.7 \\
\hline \multicolumn{4}{|l|}{ Comorbidities } \\
\hline Hypertension & $90(76.3)$ & $154(80.2)$ & 0.6 \\
\hline Diabetes & $17(14.4)$ & $28(14.6)$ & 0.97 \\
\hline Coronary artery disease & 56 (47.4) & $83(43.2)$ & 0.47 \\
\hline $\begin{array}{l}\text { Chronic obstructive } \\
\text { pulmonary disease }\end{array}$ & $30(25.4)$ & $45(23.4)$ & 0.7 \\
\hline Renal failure & $13(11.0)$ & 30 (15.6) & 0.2 \\
\hline $\begin{array}{l}\text { History of transient } \\
\text { ischemic attack/stroke }\end{array}$ & $10(8.5)$ & 21 (10.9) & 0.48 \\
\hline $\begin{array}{l}\mathrm{SD}=\text { standard deviation. } \\
{ }^{*} \text { Unless indicated otherwise. }\end{array}$ & & & \\
\hline
\end{tabular}

Table 2. In-hospital morbidity and mortality

\begin{tabular}{|lccc|} 
& \multicolumn{2}{c}{ No. (\%) of patients } & \\
\cline { 2 - 3 } Outcome & $\begin{array}{c}\text { Group A } \\
n=118\end{array}$ & $\begin{array}{c}\text { Group B } \\
n=192\end{array}$ & p value \\
\hline Death & $1(0.8)$ & $1(0.5)$ & 0.7 \\
\hline Complication & & & \\
\hline Cardiac & $13(11.0)$ & $22(11.5)$ & 0.9 \\
\hline Pulmonary & $10(8.5)$ & $20(10.4)$ & 0.7 \\
\hline Renal & $9(7.6)$ & $16(8.3)$ & 0.8 \\
\hline Infectious & $3(2.5)$ & $8(4.2)$ & 0.4 \\
\hline Gastrointestinal & $7(5.9)$ & $7(3.6)$ & 0.4 \\
\hline $\begin{array}{l}\text { Central nervous system } \\
\text { (delirium) }\end{array}$ & $8(6.8)$ & $23(12.0)$ & 0.1 \\
\hline
\end{tabular}

(Table 2). On univariate analysis, there was no significant increase in in-hospital mortality after transition to selective use of the ICU (odds ratio [OR] 1.22, 95\% CI 0.11-13.61). On univariate analysis, clinical covariates were not associated with in-hospital death (Appendix 1, Table S1, available at canjsurg.ca/012518-a1). On multivariable logistic regression, group was not associated with in-hospital death, and there were no independent predictors of inhospital death (Appendix 1, Table S2). There were also no significant differences in morbidity, with equivalent rates 
of cardiac, pulmonary and renal complications. On univariate analysis, group B had higher in-hospital morbidity (OR 2.00, 95\% CI 1.13-3.54) than group A; however, on multivariable logistic regression, this association was dampened (OR 1.75, 95\% CI 0.96-3.17). Both age and female sex were associated with morbidity in group B (Appendix 1, Table S4).

Both in-hospital deaths were attributed to cardiovascular-related causes. The first patient, in group A, was a 67 -year-old man with a $54 \mathrm{~mm}$ abdominal aortic aneurysm with a proximal neck inadequate for endovascular treatment. He had a history of hypertension, mild chronic renal failure and coronary artery disease with prior percutaneous coronary stenting. The aneurysm repair was uneventful until the aorta was unclamped. The patient then had severe and sustained hypotension with cardiogenic shock. Despite intensive medical treatment, he died on postoperative day 2 .

The second patient, in group B, was an 83-year-old man with a $76 \mathrm{~mm}$ juxtarenal AAA. He had a history of hypertension and moderate chronic renal failure. The aneurysm repair procedure was uneventful, with estimated blood loss of 1.2 L. A few hours after the procedure, the patient developed hemorrhagic shock in the recovery room and was immediately returned to the operating room. Exploration showed an actively bleeding lumbar artery, which was ligated. The patient was than admitted to the ICU, where he subsequently developed myocardial infarction. Echocardiography showed a depressed ejection fraction of $15 \%$. He underwent coronary angiography, which revealed severe 3 -vessel disease not amenable to revascularization. The patient died on postoperative day 10 .

\section{Intensive care unit admission}

After implementation of our intermediate care unit, ICU admission was avoided in 149 of 192 patients (77.6\%) in group B. Admission to the ICU was avoided by 33 of 54 patients $(61 \%)$ in 2012 (March to December), 53 of 65 patients $(82 \%)$ in 2013 and 63 of 73 patients $(86 \%)$ in 2014 (Appendix 1, Fig. S1).

Of the 149 patients initially admitted to the intermediate care unit, only $2(1.3 \%)$ were subsequently transferred to the ICU (Fig. 1). The first patient was an 81-year-old man with a history of smoking, hypertension, coronary artery disease after coronary artery bypass grafting, peripheral arterial disease and end-stage renal disease. He underwent elective repair of a $60 \mathrm{~mm}$ infrarenal AAA. On postoperative day 6 , he was admitted to the ICU for a decreased level of consciousness. He was treated for pneumonia, septic shock, acute kidney injury,

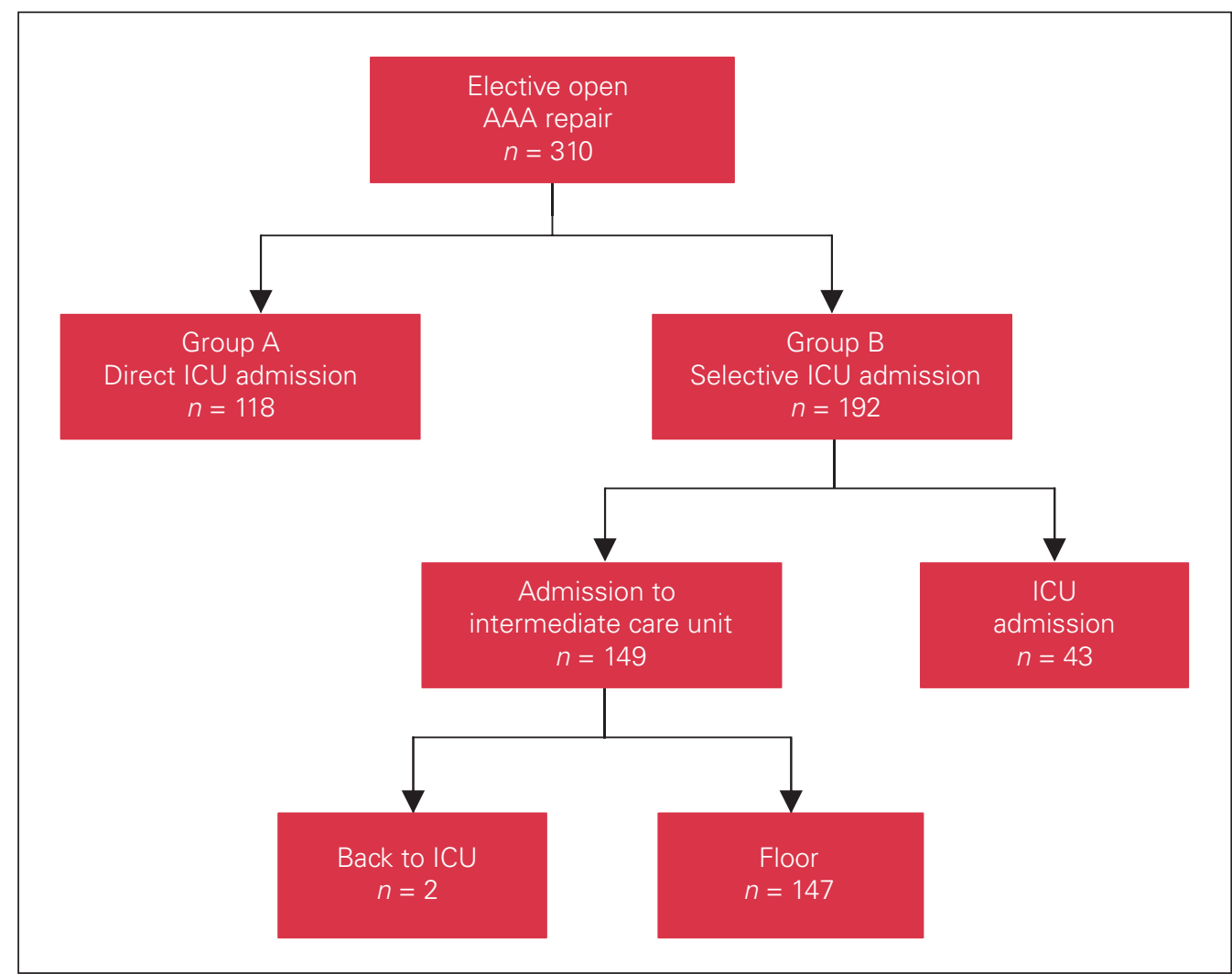

Fig. 1. Flow diagram showing postoperative course of patients with selective use of the intensive care unit (ICU) (group B) and readmission to the ICU. AAA = abdominal aortic aneurysm. 
non-ST-elevation myocardial infarction and delirium for 10 days. He subsequently recovered and was discharged home on postoperative day 23.

The second patient was a 78-year-old woman with a history of smoking, hypertension, coronary artery disease after coronary artery bypass grafting and chronic obstructive pulmonary disease. On postoperative day 3 , she was admitted to the ICU for management of a hypertensive crisis. She recovered and was discharged home on postoperative day 14.

\section{Length of stay and costs}

The mean hospital LOS was similar for groups A and B $(8.6 \mathrm{~d}$ and $8.0 \mathrm{~d}$, respectively). With routine admission to the ICU $(n=118)$, the mean ICU LOS was 2.1 days. With selective use of the ICU, the mean ICU LOS for the 43 patients who required admission to the ICU was 0.7 days. The median ICU LOS was 1.0 day in group A and 0.0 days in group $\mathrm{B}$.

On multivariable linear regression, although group did not predict ICU LOS, increasing age and RCRI score did predict ICU LOS (Appendix 1, Table S5).

Considering that the daily cost of an ICU bed is estimated at $\$ 12147,{ }^{10}$ a mean stay of 2.1 days would cost $\$ 25509$, compared to $\$ 8503$ for a 0.7-day stay. This represents a savings of roughly $\$ 17000$ per case with the selective ICU admission pathway.

\section{Discussion}

Our group did not observe an increase in mortality or morbidity among patients undergoing open AAA repair with selective ICU admission. The postoperative mortality rate was $0.6 \%$, which compares favourably with rates reported by other Canadian vascular centres. The Canadian Aneurysm Study was a multicentre study of 666 nonruptured abdominal aneurysms that were followed prospectively. ${ }^{11,12}$ The in-hospital mortality rate was $4.7 \%$, and there was a relatively low number of vascular-related complications. In another Canadian study, the in-hospital mortality rate among 230 patients undergoing open AAA repair with selective ICU admission was $2.6 \% .^{5}$ In a more recent Canadian study of 316 patients undergoing open AAA repair at a single centre, the in-hospital mortality rate was $0 \%$ and the 30 -day mortality rate, $0.5 \% .{ }^{13}$ We found no significant difference in postoperative cardiac, renal or pulmonary morbidity between patients with routine versus selective ICU admission.

We were able to avoid ICU admission in $78 \%$ of our patients, which is comparable to rates in other studies. Three studies have shown the safety of an intermediate care unit, with a net reduction of $48 \%-89 \%$ in postoperative ICU use. ${ }^{5-7}$
Our study showed a transition period in the first year of the change in policy to selective use of the ICU, with a gradual reduction in the rate of ICU admission while surgeons and nurses adapted to the change and became more comfortable with admitting patients directly to the intermediate care unit.

We observed a higher incidence of reported postoperative delirium with the selective ICU admission pathway. This is possibly a result of detection bias, with more awareness and screening of delirium noted after implementation of the pathway, as a delirium-detection protocol and nursing training were implemented with the development of the intermediate care unit. This was included in our newly formulated hospital plan to provide individualized patient care and address geriatric and frailty domains, which include an objective evaluation of delirium.

Intensive care unit beds are a scarce and costly resource in Canadian health care systems. Hospital bed prices estimated by the Quebec Ministry of Health and Social Services in 2015 were $\$ 12147$ per day for an ICU bed, $\$ 3378$ for an intermediate care unit bed and $\$ 1126$ for a regular ward bed..$^{10}$ With the LOS for the ICU versus the intermediate care unit observed in this study and these costs, about $\$ 2.5$ million theoretically could be saved to our hospital during a 24-month period.

Lawlor and colleagues 5 polled Canadian Society for Vascular Surgery members in 2003 and found that $77 \%$ still had routine admission to the ICU at their institution. At the society conference in 2015 , we polled the members to find out whether this had changed. Among the $57 \mathrm{mem}$ bers who responded, there was still a preponderance of routine admission to the ICU (58\% v. $42 \%$ for selective admission) (unpublished findings, 2015).

We have noted other advantages of implementing decentralized intermediate care beds on our vascular unit. First, patients spend the entirety of their hospital stay on the same unit, with continuity of care. Second, the presence of nurses who have received additional training for cardiac monitoring has increased the overall quality of postoperative surveillance, and these nurses act as teachers and mentors for other nurses. Third, the unit offers more surveillance for frail patients just arriving from the ICU. Finally, there has been a reduction in cancellation of cardiac and vascular procedures related to ICU bed availability, which translates to better use of the scarce resource.

\section{Limitations}

The retrospective nature of our study represents a potential source of bias. We examined only in-hospital mortality and morbidity, whereas our results may have varied if we had used other outcomes, such as 30-day or all-cause mortality. Second, the design of this cohort 
study is subject to maturation bias owing to the changes seen over time and over the 2 study periods with the advent of developments in patient care and operative technique. This was countered by the fact that we selected a relatively short period to provide an adequate number of patients.

\section{Conclusion}

Our results confirm the safety and cost-effectiveness of a selective ICU admission pathway in our hospital, with the majority of patients sent directly to an intermediate care unit. Other potential positive consequences of an intermediate care unit include continuous patient care, improved nursing care, better surveillance for frail patients and reduction of cancellation of procedures by better use of ICU resources.

Acknowledgement: The authors thank Nicole Sansregret for assistance with administrative support.

Affiliation: From the Division of Vascular Surgery, Centre hospitalier universitaire de Montréal, Montreal, Que.

Competing interests: None declared.

Contributors: D. Dion and S. Elkouri designed the study. D. Dion and S. Elkouri acquired the data, which D. Dion, L.M. Drudi, N. Beaudoin, J.-F. Blair and S. Elkouri analyzed. D. Dion, L.M. Drudi and S. Elkouri wrote the manuscript, which D. Dion, L.M. Drudi, N. Beaudoin, J.-F. Blair and S. Elkouri critically revised. All authors gave final approval of the article to be published.

Content licence: This is an Open Access article distributed in accordance with the terms of the Creative Commons Attribution (CC BY-NC-ND 4.0) licence, which permits use, distribution and reproduction in any medium, provided that the original publication is properly cited, the use is noncommercial (i.e., research or educational use), and no modifications or adaptations are made. See: https://creativecommons.org/licenses/by-nc-nd/4.0/

\section{References}

1. Schweizer A, Khatchatourian G, Höhn L, et al. Opening of a new postanesthesia care unit: impact on critical care utilization and complications following major vascular and thoracic surgery. 7 Clin Anesth 2002;14:486-93.

2. Cleary M, Cahill RA, Younis F, et al. The impact of the establishment of a surgical high dependency unit on management of abdominal aortic aneurysm. Ir 7 Med Sci 2006;175:9-12.

3. Bastounis E, Filis K, Georgopoulos S, et al. Selective use of the intensive care unit after elective infrarenal abdominal aortic aneurysm repair. Int Angiol 2003;22:308-16.

4. Ryan D, McGreal G. Why routine intensive care unit admission after elective open infrarenal abdominal aortic aneurysm repair is no longer an evidence based practice. Surgeon 2010;8:297-302.

5. Lawlor DK, Lovell MB, DeRose G, et al. Is intensive care necessary after elective abdominal aortic aneurysm repair? Can 7 Surg 2004;47:359-63.

6. Bertges DJ, Rhee RY, Muluk SC, et al. Is routine use of the intensive care unit after elective infrarenal abdominal aortic aneurysm repair necessary? 7 Vasc Surg 2000;32:634-42.

7. Podore PC, Throop EB. Infrarenal aortic surgery with a 3-day hospital stay: a report on success with a clinical pathway. 7 Vasc Surg 1999;29:787-92.

8. von Elm E, Altman DG, Egger M, et al. The Strengthening the Reporting of Observational Studies in Epidemiology (STROBE) statement: guidelines for reporting observational studies. 7 Clin Epidemiol 2008;61:344-9.

9. Lee TH, Marcantonio ER, Mangione CM, et al. Derivation and prospective validation of a simple index for prediction of cardiac risk of major noncardiac surgery. Circulation 1999;100:1043-9.

10. Bourque F. Ententes interprovinciales en assurance santé. Montreal: Régie de l'assurance maladie du Québec; 2015. Available: www.ramq. gouv.qc.ca/SiteCollectionDocuments/professionnels/infolettres/2015/ info284-4.pdf (accessed 2019 Sept. 11).

11. Johnston KW, Scobie TK. Multicenter prospective study of nonruptured abdominal aortic aneurysms. I. Population and operative management. 7 Vasc Surg 1988;7:69-81.

12. Johnston KW. Nonruptured abdominal aortic aneurysm: six-year follow-up results from the multicenter prospective Canadian Aneurysm Study. Canadian Society for Vascular Surgery Aneurysm Study Group. 7 Vasc Surg 1994;20:163-70.

13. Drudi L, Bastien L, Nault P. PC004. Revisiting the outcomes of open repair of abdominal aortic aneurysms in an era of endovascular surgery. 7 Vasc Surg 2018;67:E172-3. 